\title{
A novel insight into the pathophysiology of autoimmune hepatitis: An immune activator mutation in the FLT3 receptor
}

\author{
Muhammed Yuksel ${ }^{1,2}$, (i) Ayse Armutlu , (i) Farinaz Nazmi ${ }^{1,2}$, (i) Serdar Ceylaner ${ }^{4}$, (i) Cigdem Arikan ${ }^{1,2}$ \\ ${ }^{I}$ Paediatric Gastroenterology-Hepatology/Liver Transplantation Centre, Koc University, Istanbul, Turkey; ${ }^{2}$ Research Centre for Translational Medicine \\ (KUTTAM)-Liver Immunology Laboratory, Koc University, Istanbul, Turkey; ${ }^{3}$ Department of Pathology, Koc University Hospital, Istanbul, Turkey; \\ ${ }_{4}^{4}$ Intergen Diagnostic Centre for Genetic Disorders, Ankara, Turkey
}

\begin{abstract}
Autoimmune hepatitis (AIH) is a chronic progressive autoimmune liver disease characterized by hypergammaglobulinemia, interface hepatitis, a female preponderance, and the presence of autoantibodies in most patients. The presence of HLA-DR3/DR4 and functional impairment in regulatory T cells are associated with AIH. However, AIH is a multifactorial complex disease. This report is a description of a case of seronegative AIH in a girl with chronic hepatitis, a high immunoglobulin E (IgE) level, perforating nodular dermatitis, and sheer eosinophilia. To re-evaluate the diagnosis, whole exon sequencing was performed. It was determined that the patient had ancestral haplotype A1-B8-DR3, which is associated with autoimmunity. Importantly, it was also noted that an undocumented point mutation (Ala627Thr) of the FMS-like tyrosine 3 kinase (FLT3) receptor was present. This FLT3 receptor gain-of-function mutation is associated with the activation of the mechanistic target of rapamycin (mTOR), and dendritic cell activation. In addition, a loss-of-function mutation in the melanocortin-3 receptor gene, which inhibits interleukin 4, was detected. The constellation of these immune deregulatory factors may have propagated auto-aggression of the liver, causing chronic hepatitis with AIH features. The findings of seronegativity with eosinophilia and a high $\operatorname{IgE}$ level led us to hypothesize that the pathognomonic mechanism in this case was unlike that of classic AIH pathophysiology. Since mTOR is constitutively activated, mTOR inhibitors may be a useful option to treat $\mathrm{AIH}$ and dermatitis.
\end{abstract}

Keywords: Autoimmune hepatitis; liver disease; mutation.

\section{Introduction}

Autoimmune hepatitis $(\mathrm{AIH})$ is a chronic, progressive, autoimmune liver disease, characterized by lymphocytoplasmic infiltration concentrated in the portal areas leading to fibrosis, and eventually cirrhosis in $38 \%$ of cases. ${ }^{[1]}$ Autoantibodies, such as anti-smooth muscle actin,

How to cite this article: Yuksel M, Armutlu A, Nazmi F, Ceylaner S, Arikan C. A novel insight into the pathophysiology of autoimmune hepatitis: An immune activator mutation in the FLT3 receptor. Hepatology Forum 2021; 2(3):112-116.

Received: April 08, 2021; Accepted: May 26, 2021; Available online: September 07, 2021

Corresponding author: Cigdem Arikan; Koc Universitesi, Pediatrik Gastroenteroloji-Hepatoloji/Karaciger Nakil Merkezi, Istanbul, Turkey

Phone: +90 2123113410 e-mail: cigdemarikanmd@yahoo.com

(c) (i) OPEN ACCESS

This workis licensed undra

(C) Copyright 2021 by Hepatology Forum - Available online at www.hepatologyforum.org anti-nuclear antibody, anti-liver-kidney microsomal type 1, and antiliver cytosol type 1 , are present in more than $80 \%$ of AIH patients, in addition to hypergammaglobulinemia. ${ }^{[1]}$ However, as many as $10 \%$ of $\mathrm{AIH}$ patients are seronegative for these autoantibodies. The complete etiology of AIH remains poorly understood. It has been established that human leucocyte antigen (HLA) class II alleles, such as HLA-DR3/ DR4/DR7 and the ancestral haplotype A1-B8-DR3, are associated with AIH. ${ }^{[1,2]}$ Variations in non-HLA alleles, such as CLTA4, GATA2, and TNFA, have also been associated with $\mathrm{AIH} \cdot{ }^{[1]}$ However, genetic studies investigating the incidence of AIH in first-degree relatives and concordance in monozygotic twins demonstrated that $\mathrm{AIH}$ is a multifactorial complex disease that requires further research. ${ }^{[3]}$

\section{Case Report}

This is a case of AIH in a 12-year-old girl. She presented with signs of liver injury but without jaundice, including an elevated alanine aminotransferase level (ALT >2000 IU/L), autoantibody seronegativity, and vast peripheral eosinophilia both proportionally $(>20 \%$, normal range: $0.7-5.8 \%)$ and in terms of count $\left(1.82 \times 10^{3} / \mathrm{uL}\right.$, normal range: 0.04 $0.38 \times 10^{3} / \mathrm{uL}$ ), in addition to an elevated monocyte count (Fig. 1a-c). Furthermore, the patient had conspicuous skin lesions, diagnosed as nodular perforating dermatitis (Appendix Fig. 1a, b).

Liver histology demonstrated typical features of AIH with portal inflammation composed of multi-focal interface hepatitis with cluster of differentiation $3(\mathrm{CD} 3+\mathrm{T})$ lymphocyte, CD20+B cell, and CD38+plasma cell infiltration; a rosette formation (Fig. 2a-f); no biliary changes; and mild fibrosis (Ishak score grade 2). An AIH score of 7 was recorded according to the 2018 scoring system to diagnose pediatric autoimmune liver diseases, ${ }^{[4]}$ and defined as probable AIH (Appendix Table 1). Apart from dermatitis, no other co-morbidities were detected, including infectious pathogens (Appendix Table 2). Magnetic resonance cholangiography results were normal. Both the bone marrow aspirate and the endoscopy findings were unremarkable, and did not support an aberrant eosinophilic infiltration, which excluded hypereosinophilic syndrome. Standard immunosuppressive therapy (steroids/azathioprine) was initiated according to AIH guidelines. ${ }^{[1]}$ Specifically, the initial treatment consisted of $60 \mathrm{mg} /$ day steroids, tapered in the following 4 weeks to 5 $\mathrm{mg}$ /day, but subsequently increased to $10 \mathrm{mg}$ /day. Azathioprine $(50 \mathrm{mg} /$ day) was initiated and increased to $100 \mathrm{mg}$ /day. The patient responded to the treatment; there was an alanine aminotransferase decrease of $>90 \%$ to $100-200 \mathrm{IU} / \mathrm{L}$ within 4 weeks (Fig. 1a). Low-grade fluctuating hepatitis, high IgE, the reappearance of sheer eosinophilia, (Fig. 1b) and high blood monocyte counts at diagnosis and thereafter (Appendix 


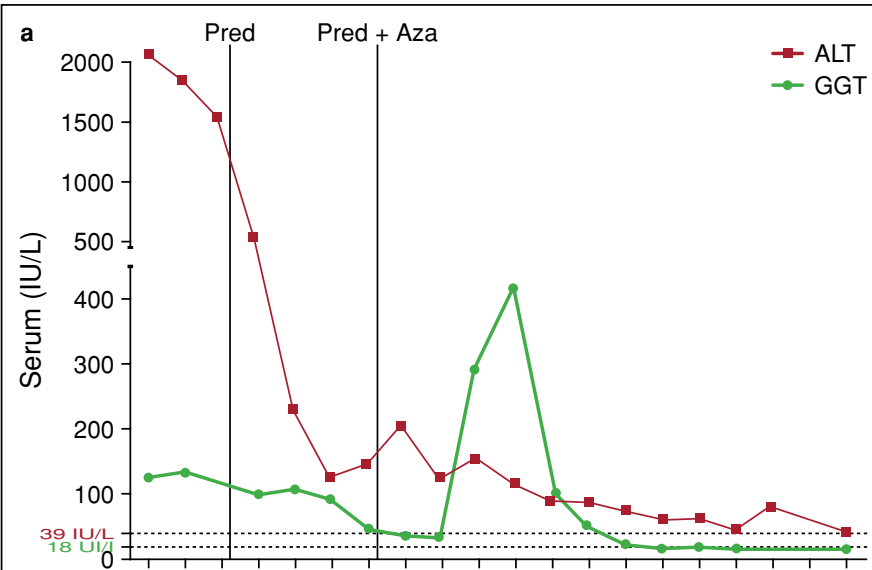

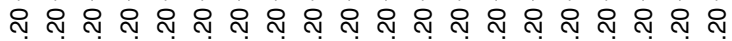

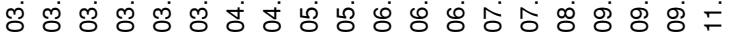

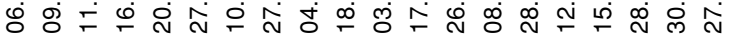

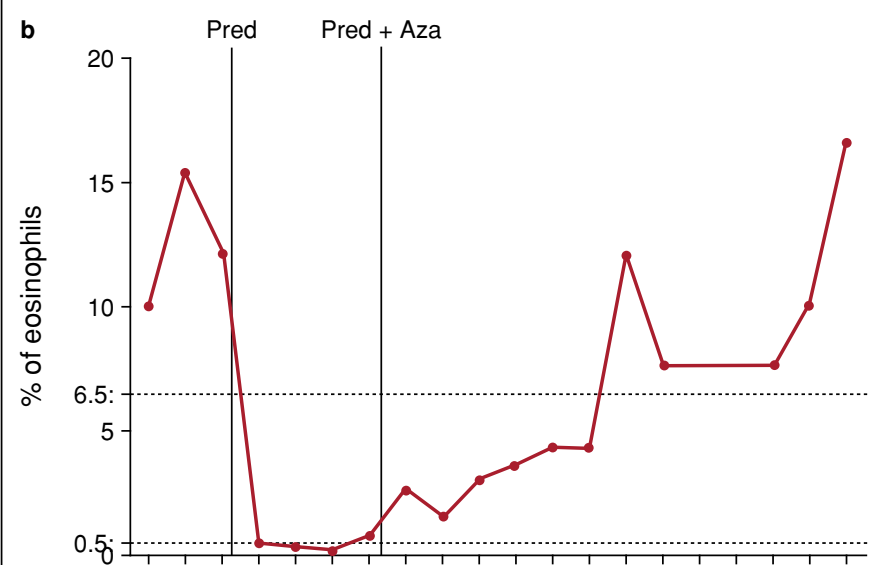

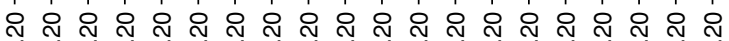
\% \%

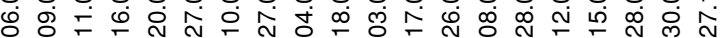

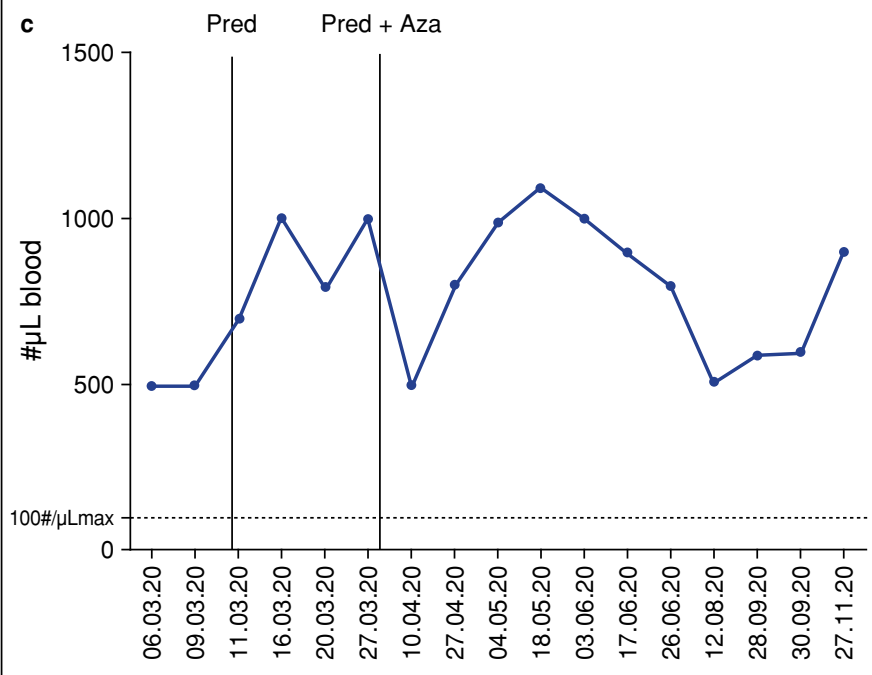

Figure 1. Change in liver enzymes and immune cells. (a) The course of alanine transaminase (ALT) and gamma glutamyltransferase (GGT) measurements. Prednisolone (Pred) treatment was initiated at diagnosis, followed by azathioprine (Aza). (b) The change in the blood percentage of eosinophils. (c) The fluctuation in the blood monocyte count.

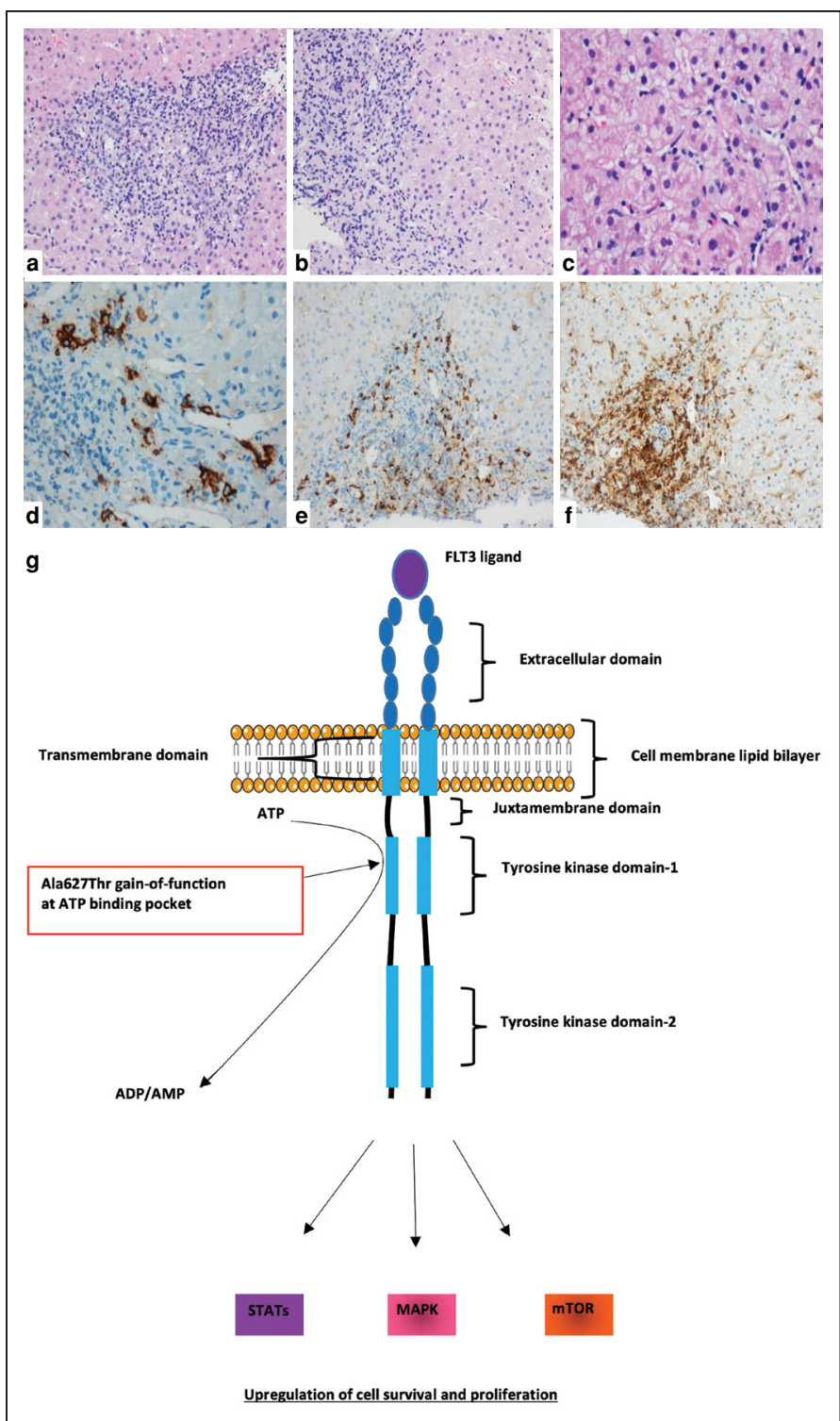

Figure 2. Liver histology and putative FLT3 mutation-mediated immune pathways. (a) Injury pattern of chronic hepatitis with prominent portal inflammation composed of lymphocytes and plasma cells (H\&E x100); (b) Multifocal marked periportal interface activity (interface hepatitis) (H\&E x200); (c) Hepatocyte rosettes with mild lobular activity (H\&E x400). (d) Immunohistochemistry staining with CD38+ plasma-cell marker (IHC x200); (e) CD20+ B cells; and (f) immunohistochemistry images demonstrating predominant CD3+ $T$ cells within the mixed population of lymphocytes (IHC x100). (g) The FLT3-receptor subunits are the extracellular domain, the transmembrane domain, the juxtamembrane domain, and the proximal and distal tyrosine kinase domains. Ligand binding to the FLT3 receptor results in the homodimerization and subsequent trans-autophosphorylation of the tyrosine residues, eventually increasing cell survival and proliferation through STAT, MAPK, and mTOR activation. A point mutation at amino acid 627, which is located at the adenosine triphosphate (ATP) binding pocket, results in switching alanine to threonine (Ala627Thr). ATP is likely more rapidly consumed, with enhanced phosphorylation as a result.

Table 3) prompted us to re-evaluate the initial diagnosis based on a suspicion of an immune dysregulation. Whole exon sequencing (WES) was performed and the results demonstrated that the patient had the ancestral haplotype A1-B8-DR3 (associated with AIH), a loss-of-func- 
tion mutation in the MC3R gene, and a hitherto undocumented gainof-function mutation (Ala627Thr) of the FMS-like tyrosine 3 kinase (FLT3) receptor gene.

\section{Discussion}

The classic presentation of AIH does not include a high IgE count, shear eosinophilia, perforating nodular dermatitis, or borderline monocytosis. In this case, the atypical presentation led us to conduct a comprehensive investigation. WES revealed different (novel) pathological mutations that potentially explained the findings. To the best of our knowledge, this is the first known instance of a gain-of-function mutation in the FLT3 receptor oncogene in a child with AIH. FLT3 has critical roles in regulating immune homeostasis. It is a transmembrane-bound receptor tyrosine kinase and is activated by the FLT3 ligand (FLT3L) (Fig. 2g). ${ }^{[5]}$ FLT3L binding leads to dimerization of the FLT3 receptor and activation of downstream kinase-signaling pathways, including the mitogen-activated protein kinase (MAPK), signal transducer and activator of transcription (STAT), and mammalian target of rapamycin (mTOR) pathways. This mutation likely causes excess phosphorylation-mediated over-activation of the receptor, conceivably leading to uncontrolled innate and adaptive immune activation. Gain-of-function mutations of the FLT3 receptor have been reported to have expanded dendritic cells (DCs), which stimulated the proliferation of $\mathrm{T}$ cells and regulatory $\mathrm{T}$ cells (Tregs). ${ }^{[6]}$ Our patient had the A1-B8-DR3 haplotype. HLA-DR3/ HLA-DR4, as well as A1-B8-DR3, has been linked with Tregs functional impairment in mice and humans. ${ }^{[2,7,8]}$ This combination could cause a loss of tolerance in T cells and, potentially facilitating autoimmunity in the liver and leading to AIH.

In addition, our patient had dermatitis, which could also be linked to over-activated FLT3 receptor-mediated DC accumulation. Yan et al. ${ }^{[9]}$ reported that in mice, use of an FLT3 inhibitor decreased the number and activation of DCs and led to improvement in skin lesions. In addition to FLT3-related immune dysregulation, the loss-of-function mutation of the MC3R gene could also explain dermatitis, a high $\operatorname{IgE}$ count, and eosinophilia. This mutation has often been linked to obesity in humans, but it has also been shown that the interaction between MC3R and its ligand, $\alpha$-melanocyte-stimulating hormone ( $\alpha$-MSH), suppressed atopic dermatitis in a mouse model. Also, $\alpha-\mathrm{MSH}$ reduced the eosinophil count and the serum level of IgE, IL-4, and IL-5 in asthmatic mice. ${ }^{[10]}$ We concluded that MC3R activity appeared to have an anti-TH2 effect and a mutation of this gene may have caused the atopic dermatitis seen in our patient.

In conclusion, it is likely that this patient requires close monitoring, as she is at increased risk of developing leukemia. Most importantly, it is noteworthy that seronegative AIH co-occurring with a high $\operatorname{IgE}$ count and eosinophilia led us to wonder if the pathognomonic mechanisms involved in this case led to a presentation unlike the classical
AIH pathophysiology. mTOR inhibitors may be a useful drug option to treat autoimmunity, dermatitis, and eosinophilia. Genetic alterations that lead to immune dysregulation should be a consideration in children with seronegative AIH and eosinophilia.

Informed Consent: Written, informed consent was obtained from the patient's family for the publication of this case report and the accompanying images.

Peer-review: Externally peer-reviewed.

Author Contributions: MY, AA, FN, SC and CA designed, conceived, supervised and wrote the manuscript. FN, SC, MY, AA and CA collected, processed and/or interpreted the results and AA was responsible of the histology results. All authors critically reviewed the manuscript.

Conflict of Interest: The authors have no conflict of interest to declare.

Financial Disclosure: The authors declared that this study has received no financial support.

\section{References}

1. Mack CL, Adams D, Assis DN, Kerkar N, Manns MP, Mayo MJ, et al. Diagnosis and management of autoimmune hepatitis in adults and children: 2019 practice guidance and guidelines from the american association for the study of liver diseases. Hepatology 2020;72(2):671-722. [CrossRef]

2. Nouri-Aria KT, Donaldson PT, Hegarty JE, Eddleston AL, Williams R. HLA A1-B8-DR3 and suppressor cell function in first-degree relatives of patients with autoimmune chronic active hepatitis. J Hepatol 1985;1(3):235-241.

3. Lammert C. Genetic and Environmental Risk Factors for Autoimmune Hepatitis. Clin Liver Dis (Hoboken) 2019;14(1):29-32. [CrossRef]

4. Mieli-Vergani G, Vergani D, Baumann U, Czubkowski P, Debray D, Dezsofi A, et al. Diagnosis and management of pediatric autoimmune liver disease: espghan hepatology committee position statement. J Pediatr Gastroenterol Nutr 2018;66(2):345-360. [CrossRef]

5. Staudt D, Murray HC, McLachlan T, Alvaro F, Enjeti AK, Verrills NM, et al. Targeting oncogenic signaling in mutant FLT3 acute myeloid leukemia: the path to least resistance. Int J Mol Sci 2018;19(10):3198. [CrossRef]

6. Lau CM, Nish SA, Yogev N, Waisman A, Reiner SL, Reizis B. Leukemia-associated activating mutation of Flt3 expands dendritic cells and alters T cell responses. J Exp Med 2016;213(3):415-431. [CrossRef]

7. Yuksel M, Wang Y, Tai N, Peng J, Guo J, Beland K, et al. A novel "humanized mouse" model for autoimmune hepatitis and the association of gut microbiota with liver inflammation. Hepatology 2015;62(5):1536-1550. [CrossRef]

8. Yuksel M, Xiao X, Tai N, Vijay M, Gülden E, Beland K, et al. The induction of autoimmune hepatitis in the human leucocyte antigen-DR4 nonobese diabetic mice autoimmune hepatitis mouse model. Clin Exp Immunol 2016;186(2):164-176. [CrossRef]

9. Yan HX, Li WW, Zhang Y, Wei XW, Fu LX, Shen GB, et al. Accumulation of FLT3(+) CD11c (+) dendritic cells in psoriatic lesions and the anti-psoriatic effect of a selective FLT3 inhibitor. Immunol Res 2014;60(1):112-126

10. Moscowitz AE, Asif H, Lindenmaier LB, Calzadilla A, Zhang C, Mirsaeidi $\mathrm{M}$. The importance of melanocortin receptors and their agonists in pulmonary disease. Front Med (Lausanne) 2019;6:145. [CrossRef] 


\section{Appendices}

\begin{tabular}{|c|c|c|c|}
\hline Parameter & Feature & Score for AlH & Case \\
\hline \multirow[t]{2}{*}{ ANA and/or SMA } & $\geq 1: 20$ & +1 & \multirow{2}{*}{0} \\
\hline & $\geq 1: 80$ & +2 & \\
\hline \multirow[t]{2}{*}{ Anti-LKM1 titres } & $\geq 1: 10$ & +1 & \multirow{2}{*}{0} \\
\hline & $\geq 1: 80$ & +2 & \\
\hline Anti-LC1 & Positive & +2 & 0 \\
\hline Anti-SLA & Positive & +2 & 0 \\
\hline pANNA & Positive & +1 & 0 \\
\hline \multirow[t]{2}{*}{ Serum IgG (x ULN) } & $>U L N$ & +1 & \multirow{2}{*}{+1} \\
\hline & $>1: 20$ ULN & +2 & \\
\hline \multirow[t]{2}{*}{ Liver histology } & Compatible with AlH & +1 & \multirow{2}{*}{+2} \\
\hline & Typical of AlH & +2 & \\
\hline Absence of viral hepatitis (A, B, E, EBV), NASH, Wilson's disease, and drug exposure & Yes & +2 & +2 \\
\hline Presence of extrahepatic autoimmunity & Yes & +1 & 0 \\
\hline Family history of autoimmunity & Yes & +1 & 0 \\
\hline \multirow[t]{2}{*}{ Cholangiography } & Normal & +2 & \multirow{2}{*}{+2} \\
\hline & Abnormal & -2 & \\
\hline Total & & & +7 \\
\hline \multicolumn{4}{|l|}{ Total score } \\
\hline \multicolumn{4}{|l|}{ 27: Probable AlH } \\
\hline \multicolumn{4}{|l|}{ >8: Definite AlH } \\
\hline
\end{tabular}

\begin{tabular}{lll}
\hline Appendix Table 2. Microbiology and virology & & \\
\hline Parameter & Value & Reference value(s) \\
\hline Hepatitis C virus antibody & 0.06 (Negative) & $<1$ \\
Hepatitis B virus surface antigen (HbsAg) & 0.19 (Negative) & $<1$ \\
Hepatitis B virus surface antibody & 24.49 & $>10 \mathrm{mIU} / \mathrm{mL}$ for immunity \\
Anti-HIV1 & 0.04 & $<1$ \\
Coronavirus, SARS-CoV-2 RNA (PCR test) & Negative & n/a \\
Protozoon & Negative & $\mathrm{n} / \mathrm{a}$ \\
Entamoeba histolytica & Negative & $\mathrm{n} / \mathrm{a}$ \\
Giardia lamblia & Negative & $\mathrm{n} / \mathrm{a}$ \\
Cryptosporidium parvum & Negative & $\mathrm{n} / \mathrm{a}$ \\
Trichinella spiralis IgM & Negative & $\mathrm{n} / \mathrm{a}$ \\
Toxocara canis antibodies & Negative & $<10$ (MONA) \\
Ascaris IgG & 8.0 & $<1: 40$ \\
Fasciola hepatica antibodies & $<1: 40$ (Negative) & $<1: 160$ \\
Echinococcus granulosus & $<1: 160$ (Negative) & $\mathrm{n} / \mathrm{a}$ \\
\hline Tuberculosis feron test & Negative & \\
\hline
\end{tabular}

HIV: Human immunodeficiency virus; Ig: Immunoglobulin; MONA: Multiple of normal activity; n/a: not applicable; PCR: Polymerase chain reaction; SARS-CoV-2: Severe acute respiratory syndrome coronavirus 2 . 


\begin{tabular}{lcl}
\hline \multicolumn{2}{l}{ Appendix Table } & 3. Leukocyte subtypes at diagnosis \\
\hline Parameter & Present case & Range \\
\hline CD3+ T cells & 1757 & $800-3500$ (cells/uL) \\
CD4+ T cells & 1101 & $400-2100$ (cells/uL) \\
CD8+ T cells & 452 & $200-1200$ (cells/uL) \\
CD14+ Monocytes & 501 & $0-100$ (cells/uL) \\
CD20+ B cells & 960 & $350-3200$ (cells/uL) \\
CD56+ NK cells & 320 & $25-1750$ (cells/uL) \\
\hline
\end{tabular}

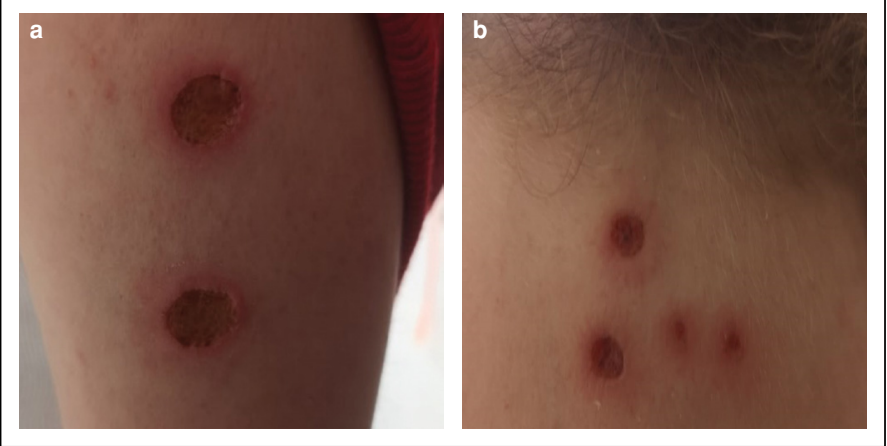

Appendix Figure 1. Nodular perforating dermatitis. (a, b) Photos of the ulcerative skin lesions on the arm and forehead. 